\title{
Design and Testing of Building Integrated Hybrid Vertical Axis Wind Turbine
}

\author{
Gwani Mohammed*, Abubakar Ibrahim, Umar Mohammed Kangiwa, Joshua Benjamin Wisdom
}

Department of Physics, Kebbi State University of Science and Technology, Aliero, Nigeria

Email address:

gwanimohammed@gmail.com (G. Mohammed)

${ }^{*}$ Corresponding author

\section{To cite this article:}

Gwani Mohammed, Abubakar Ibrahim, Umar Mohammed Kangiwa, Joshua Benjamin Wisdom. Design and Testing of Building Integrated Hybrid Vertical Axis Wind Turbine. Journal of Electrical and Electronic Engineering. Vol. 9, No. 3, 2021, pp. 69-77.

doi: $10.11648 /$ j.jeee.20210903.12

Received: January 26, 2021; Accepted: April 20, 2021; Published: June 3, 2021

\begin{abstract}
Building integrated wind turbine are considered as part of a group of technologies that are suitable for domestic micro-energy generation. Darrieus and Savonius turbines work efficiently in the urban environment at low wind speed, the Savonius rotor is self-starting and creates high torque but has low efficiency, while the Darrieus rotor is very efficient but does not self-start easily. Thus, the combination of these rotors as hybrid system would help to improve the overall efficiency of the wind turbines. The aim of this paper was to design, fabricate and experimentally investigate the performance of hybrid Vertical Axis Wind Turbine (VAWT) on residential buildings. A building model with gable rooftop was design and fabricated for use in testing of the hybrid VAWT. The height of the hybrid VAWT was paced at $Y=150 \mathrm{~mm}$ above the rooftop. The results obtained from the studies showed that the hybrid VAWT mounted on the building rooftop yield up to $63 \%$ more energy compared to the bare-hybrid VAWT (without building). Similar improvement in performance of the hybrid VAWT is also observed in the rotational speed, mechanical power and the coefficient of torque, where the building integrated hybrid VAWT outperformed the bare-hybrid VAWT. Thus the results indicate that urban buildings are suitable for the mounting of the hybrid VAWT.
\end{abstract}

Keywords: Hybrid VAWT, Wind Energy, Rooftop, Vaulted Building

\section{Introduction}

Satisfying the energy demand of the built environment, reducing the carbon foot print, and provision of decentralized energy generation are some of the potential benefit of deploying wind turbines in the urban environment $[1,2]$. The energy captured from the wind is a pollution-free resource, and could help in reducing the dependence on fossil fuel [3]. Difficulties experienced in installing wind turbines on the rooftop of metropolitan building have led to overriding concern in estimating, with a certain degree of accuracy, the yield expected from a wind turbine in a particular location in the urban environment [4]. The poor performance of wind turbines in the urban settings is attributed to two reasons: designing wind turbine without taking into consideration the complex nature of the wind resource at the roof level and poor placement of wind turbine on the rooftop [5]. To overcome these difficulties, there is a need for an efficient design of a wind turbine that is cost-effective, simple to manufacture in a variety of different sizes, and energy outputs and can operate effectively in areas with complex wind conditions. Accordingly, quite a number of recent studies have emphasized on designing wind turbines explicitly for urban applications [6-8]. In addition, accurate methods of evaluating the variability of the wind resource across wide urban areas have been also reported [9-12]. Wind energy development in the urban environment has unique challenges due to the complex wind conditions and the surrounding obstacles of the urban environment [13]. However these challenges could be overcome when wind turbines are integrated on the rooftops of urban buildings where the performance of the wind turbine is expected to improve due to the accelerating effect at the rooftop. The Savonius and the Darrieus vertical axis wind turbine (VAWT) are the two categories of vertical axis wind turbines that are mostly installed in the urban environment. 
However these two distinct types of wind turbines have their merits and demerits. Both the Savonius rotor and the Darrieus rotor work efficiently in the urban environment at low wind speed. The Savonius rotor is self-starting and creates high torque but it has low efficiency, while the other hand the Darrieus rotor is very efficient but has difficulty to self-start. The combination of the Savonius rotor and $\mathrm{H}$ Darrieus rotor as hybrid system can improve the overall efficiency of the wind turbines. The H- Darrieus rotor VAWTs are still more preferable for operation in a complex wind environment since the wind vector at a rooftop is not horizontal. Therefore wind turbines on a roof operate in a skew flow [14]. The aim of this study was to design and investigate the performance of the hybrid VAWT integrated on the rooftop of urban building for on-site energy generation.

\subsection{Literature Review}

Wind turbines have been recognized for their potentials to produce clean and inexhaustible energy since the early energy crisis in the 1970s. The dependency on fossil fuel reserves alone has renewed the interest in the development of wind energy devices which emanated from our concern of the impending world economic crisis $[15,16]$. Before now the HAWT is the only proven technology for the generation of power from wind [17] because the Darrieus VAWT could not compete due to their low efficiency compared to the HAWT until the introduction of the VAWT (Giromill) with variable pitch configuration which has a coefficient of power value comparable to that of the HAWT [15]. The cost of generating power using the Darrieus VAWT was $18-39 \%$ less than the HAWT, subject to variation of turbine size and mean wind speed at the site [18]. The blades of the vertical rotor are the main reason for the low performance of the conventional VAWT. During operation, the blades experience rapid changes in the angle of attack (AOA) as the blades rotate in the upwind and downwind regions, the complex aerodynamic and cyclic torque issues is caused by the variation in the AOA during operation and these issues are not suffered by the HAWT blades [15].

\subsection{Darrieus Rotor}

The Darrieus rotor consists of vertical airfoils mounted on a vertical shaft at some distance or radius from the shaft. These wind turbines take advantages of the lift generated by the airfoils moving through the wind. It has advantage of higher rotational speed and high power coefficient but it has poor self-starting capabilities [19]. However, recent studies in the development of vertical axis wind energy devices have contributed to better performance and are more reliable. According to Dominy et al. [20] and Hill et al. [21] have shown that the use of fixed geometry and symmetrical airfoil will enable H-rotor VAWT to self-start by itself. Kirke [22] reported that the self-starting torque problem of the VAWTs can be overcome by using a passive variable pitch or by a combination of suitable blade airfoils. Further studies by
Takao et al. [23] has shown that the power coefficient of the VAWT can be increased by 1.5 times by placing a guide vane row upstream of the rotor, Kim and Gharib [24] and Stout et al. [25] experimentally investigated the effects of an upstream flat deflector on the power output of two counterrotating straight-bladed Darrieus wind turbine. The Darrieus rotor is as shown in Figure 1.

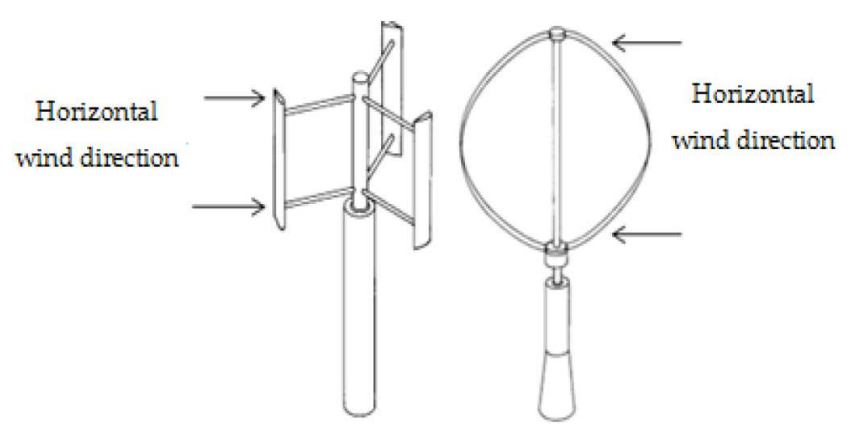

Figure 1. Darrieus rotor [1].

\subsection{Savonius Rotor}

Savonius rotor is a vertical axis wind turbine which accepts wind from any direction and self-starts at low cut in speeds. This is considered as one of the advantages of the Savonius rotor; however it has low efficiency compared to the Darrieus rotor. The Savonius rotor can be single stage, double stage or even triple stage and the starting torque of the Savonius rotor is never negative [26]. Sanusi et al. [27] combines the two geometries of the surface curve of Savonius bucket with the concave side being half a circle and the other side being of convex semi-circular form, their results showed that the combined blades improved the performance of the Savonius rotor. Thiyagaraj et al. [28] improved the efficiency and the torque values along the angular position of the Savonius rotor by placing additional blades in front of the concave side of the main rotor blade. Sharma and Sharma [29] asserted that using multiple quarter blades instead of single blades can significantly improve the performance of the Savonius rotor. Furthermore placing two deflectors upstream of the Savonius rotor can increase increased the power coefficient of the rotor as reported by [30]. The schematic diagram and CAD design of the Savonius rotor is shown in Figure 2.
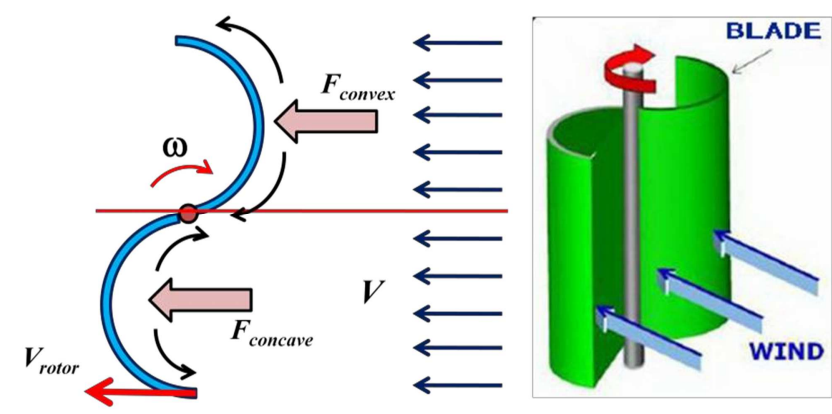

Figure 2. Schematic drawing showing the drag forces exerted on 2-blade Savonius [31]. 


\subsection{Hybrid Vertical Axis Wind Turbine}

Hybrid vertical axis wind turbine simply combines the Darrieus and Savonius rotor in order to utilize their respective advantages while overcoming their respective disadvantages. The Darrieus rotor usually has a high power coefficient and is usually more efficient compared to other types of VAWT designs but it not capable of self-starting by itself [32], while the Savonius rotor has high starting torque which enables it to self-start by it-self; however it has low rotational speed and power coefficient. To overcome these challenges, many researchers combine the Darrieus and the Savonius rotor as a compact system in order to utilize their merits while attempting to overcome their respective demerits. Many studies have been conducted on the hybrid VAWT for small scale power generation. Letcher [33] developed a small scale wind turbine optimized for low wind speed results from his studies showed that the combined rotors increases the total power of the turbine in lower wind speed. A hybrid VAWT was designed and developed by Alam and Iqbal [19]. Sahim et al. [34] investigated the effect of radius rotor in the combined Darrieus-Savonius wind turbine. Results obtained from their studies showed that the radius ratio has a significant influence on the turbine performance. Siddiqui et al. [35] experimentally investigated the performance of Hybrid vertical axis wind turbine, their results showed that the combination of the turbines in any arrangement resulted in an improved coefficient of performance and lower cut-in speed. Gwani et al. [36] compared the performance of hybrid and conventional $\mathrm{H}$ Darrieus VAWT under four wind speed conditions (V $=4.8$ $\mathrm{m} / \mathrm{s}, 4.5 \mathrm{~m} / \mathrm{s}, 4.30 \mathrm{~m} / \mathrm{s}$, and $3.90 \mathrm{~m} / \mathrm{s}$ ). The results obtained from the study indicated that the $\mathrm{C}_{\mathrm{P}}$ values of the hybrid VAWT increases by $92 \%$ compared to the H-rotor VAWT at $4.8 \mathrm{~m} / \mathrm{s}$. Further results showed similar increase in the $\mathrm{C}_{\mathrm{p}}$ values of the hybrid VAWT is also observed for other wind speed. Wekesa et al. [37] experimentally investigated the performance of VAWT rotors i.e. H-Darrieus and Savonius rotor. They carried out a systematic analysis on flow regime, rotor configuration and effects of number of blades. A result from the study reveals that these parameters have significant impact on the performance of the wind turbine, and that the H-Darrieus rotor has higher efficiency compared to the Savonius rotor. Hossein and Goudarzi [38] evaluated the performance of an innovative hybrid VAWT using 2 bladed modified Savonius Bach-type rotor and a 3-bladed Darrieus rotor, and compared their results with H-rotor Darrieus VAWT. The results obtained showed that the H-rotor Darrieus VAWT attained a maximum $\mathrm{C}_{\mathrm{p}}$ value of $48.4 \%$, but experience low starting torque while the hybrid VAWT has a highest $C_{P}$ of $41.4 \%$ with a high starting torque which improve self-starting capabilities of the hybrid VAWT.

\subsection{Building Integrated Wind Turbine}

Integrating wind turbine in urban buildings has attracted increasing attention as part of a group of technologies that are suitable for domestic micro-generations [39]. Wind turbines integrated onto urban building encompasses different challenges when compared to stand-alone wind energy systems and wind farms [40]. These challenges include low wind speed conditions of the urban areas, high levels of aerodynamic noise and turbulence generated by the wind turbines [41].

Roof shapes have different effects on the airflow above buildings, The shape of the roof is one of the main factors that affect the performance of roof mounted wind turbines and understanding it effects is very vital in planning for building integrated wind turbine [12, 42, 43]. Features of the built environment such as shape of the roof on the buildings, passage under elevated bottom, and between two buildings and building edges can concentrate wind flow [44]. A review of the past research indicates that the positioning relative to the prevailing wind direction and positioning (height above the roof ridge) affects the performance of wind turbine in the urban buildings $[39,45]$. The wind speed experienced by a wind turbine on the rooftop is about $20 \%$ higher than the undisturbed wind speed [1, 46]. Mithranene [47] reported that rooftop wind turbines have the potential to reduce the energy and carbon intensity of New Zealand electricity by $81 \%$ and $61 \%$ respectively. Abohela et al. [48] reported that integrating wind turbine on a vaulted rooftop would yield $56 \%$ more electricity than a freestanding wind turbine in the same location under the same wind conditions.

Mounting wind turbines in urban buildings can be seen as an opportunity in harvesting wind power because the wind flow can be augmented locally due to concentration effects of the buildings [40]. Mounting position and height is very important when siting wind turbines in urban environments. Blackmore [43] and Abohela et al. [48] reported that the power output of a roof mounted wind turbine may be close to zero for substantial periods of time if the turbine is mounted at the wrong position. Wind turbines can be mounted on high rise buildings and generally, high rise buildings are built with a flat rooftop. Ledo et al. [42] asserted that the profile of the roofs determines the wind flow characteristics. The wind flow in and around high-rise buildings was analyzed by $\mathrm{Lu}$ and Sun [41]. They recommended that the annual wind flows over buildings should be model using an integrated method of both macro and micro aspects. Loganathan et al. [49] Design and study the economic feasibility of micro wind turbine for residential buildings.

In this study a hybrid VAWT was design and integrated on a building rooftop in order to take advantage of the increased wind speed at the rooftop. However, to the best of the author's knowledge, no hybrid VAWT was integrated on rooftop, most the VAWTs designs are either single Darrieus or Savonius rotor integrated on the rooftop or as stand-alone system. Also the connecting struts of the hybrid VAWT are airfoil shaped during fabrication, this helps to reduce the parasitic drag experience by conventional VAWTs, and improve the aerodynamic performance of the hybrid VAWT.

The performance of a wind turbine is mostly characterized by the coefficient of power $\left(\mathrm{C}_{\mathrm{P}}\right)$, coefficient of torque, and the tip speed ratio. The coefficient of power, $C_{\mathrm{p}}$ which 
represents the efficiency of a wind turbine can be calculated using Equation (1).

$$
\mathrm{C}_{\mathrm{P}}=\frac{P}{\text { 0.5. } \cdot A \cdot U_{\infty}^{3}}
$$

Where

$P=$ the power $(\mathrm{W})$;

$\rho=\operatorname{density}\left(1.23 \mathrm{~kg} / \mathrm{m}^{3}\right)$;

$A=$ area of the rotor $\left(\mathrm{m}^{2}\right)$; and

$U_{\infty}=\mathrm{m}$ wind speed $(\mathrm{m} / \mathrm{s})$.

The $\mathrm{C}_{\mathrm{p}}$ is the ratio of the actual power that is extracted by the wind rotor to the theoretical power that is available in the wind. The $\mathrm{C}_{\mathrm{p}}$ varies from different wind turbines available; a $C_{P}$ value of $59.3 \%$ is the maximum theoretical value that a wind turbine can attain according to the Beltz limit. The tip speed ratio is related to the rated wind speed it is given by;

$$
\lambda=\frac{w r}{U}
$$

Where $\mathrm{w}$ is the angular velocity, and $\mathrm{r}$ is the radius of the turbine

The coefficient of torque which is the ratio of the torque developed and the theoretical torque available it is expressed as

$$
\mathrm{C}_{\mathrm{Q}}=\frac{c p}{\lambda}
$$

Where $\mathrm{C}_{\mathrm{Q}}$ is the coefficient of torque

\section{Materials and Method}

\subsection{Description of the Hybrid VAWT Design}

The main design parameters of the hybrid VAWT consist of five components: blades, main link, shaft, generator and the Savonius rotor. Figure $3 \mathrm{a}$, and $\mathrm{b}$ show the blades of the $\mathrm{H}$-Darrieus rotor and Savonius rotor. The H-Darrieus rotor consists of three main vertical blade and six supporting struts (Figure 4a). The profile for the vertical blade is symmetrical aerofoil, NACA 0015. The chord length and the height of the vertical blades are $5 \mathrm{~cm}$ and $40 \mathrm{~cm}$, respectively, while the width and the span length of the supporting struts are $3.4 \mathrm{~cm}$ and $15 \mathrm{~cm}$, the diameter of both the H-rotor and Savonius rotor is $35 \mathrm{~cm}$ and $27 \mathrm{~cm}$ respectively as shown in Table 1. The supporting struts of the VAWT connect the central rotating column to the blades. A double stage Savonius rotor was inserted in the middle of the H-Darrieus rotor to form the hybrid VAWT as shown in Figure $4 \mathrm{~b}$. The shaft which is made of steel of diameter $5 \mathrm{~mm}$ is located at the center of the $10 \mathrm{~W}$ generator. The computer aided design (CAD) of the $\mathrm{H}$ Darrieus and Savonius rotor and the complete assembly of the hybrid VAWT are shown in Figure $4 \mathrm{a}$, and $\mathrm{b}$ and Figure 5 respectively. The lab scale model is presented in Figure 6, while the design specification of the hybrid VAWT is presented in Table 1.

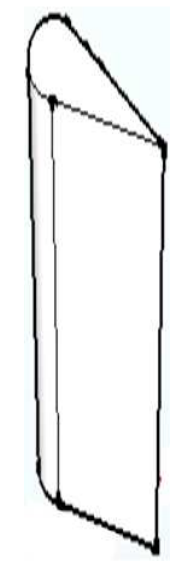

(a)

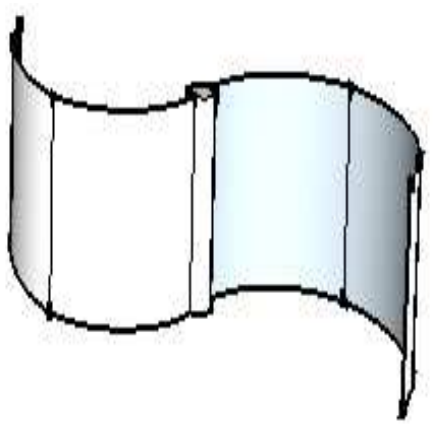

(b)

Figure 3. (a) VAWT blade, (b) Savonius blade.

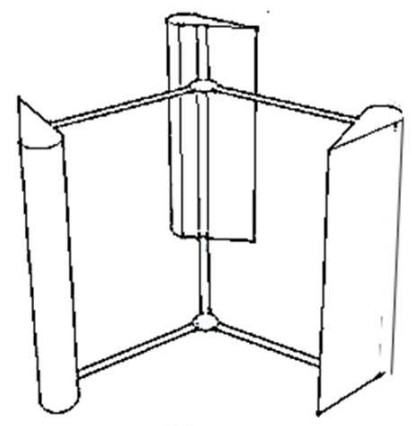

(a)

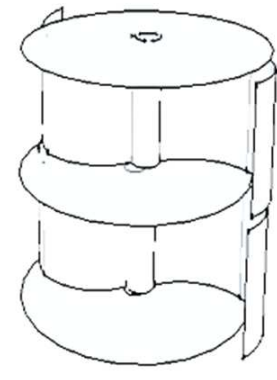

(b)
Figure 4. CAD design of the (a) H-rotor VAWT, (b) Savonius rotor.

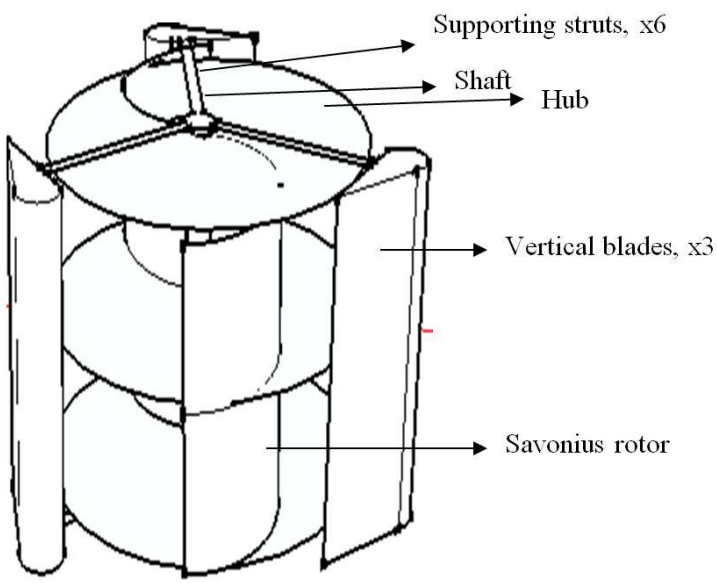

Figure 5. CAD Design for the complete assembly of the hybrid VAWT. 


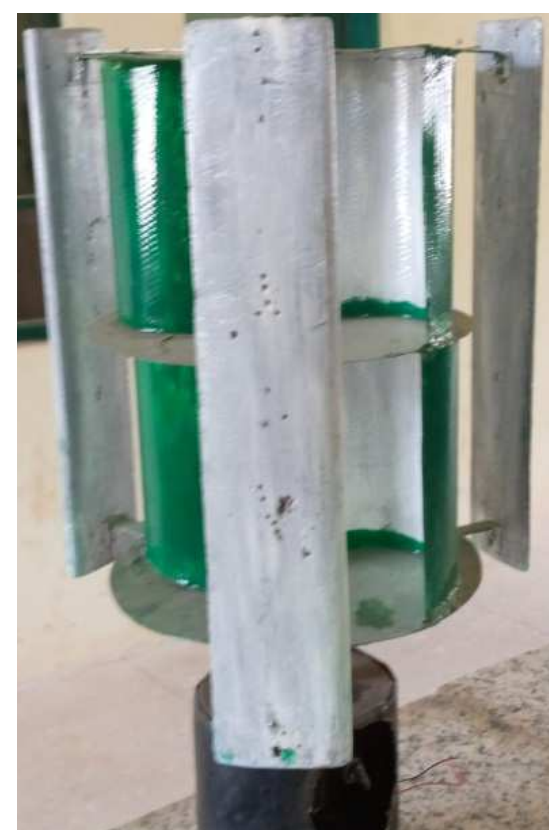

Figure 6. Lab scale hybrid VAWT showing various design components.

Table 1. Specification of the hybrid VAWT.

\begin{tabular}{ll}
\hline Geometry of the turbine & Dimension \\
\hline Type of aerofoil & Symmetrical aerofoil \\
Profile of aerofoil & NACA 0015 \\
Height of vertical blade, $h(\mathrm{~cm})$ & 40 \\
Diameter of Darrieus rotor $d(\mathrm{~cm})$ & 35 \\
Chord length of vertical blade, $c_{v}(\mathrm{~cm})$ & 8 \\
Length of supporting struts, $l(\mathrm{~cm})$ & 15 \\
width of supporting struts, $w(\mathrm{~cm})$ & 3.4 \\
Height of the Savonius rotor $(\mathrm{cm})$ & 18 \\
Diameter of the Savonius rotor $(\mathrm{cm})$ & 27 \\
\hline
\end{tabular}

\subsection{Experimental Set-up and Procedure}

A building model with vaulted roof shape was designed and fabricated in the experiment. The building model has a height, length, and width of $1480 \mathrm{~mm} \times 1700 \mathrm{~mm} \times 800 \mathrm{~mm}$ as shown in Figure 6. The hybrid VAWT was placed $150 \mathrm{~mm}$ above the vaulted rooftop which is equivalent to $1630 \mathrm{~mm}$ from the ground level. The building model with the hybrid VAWT is shown in Figure 7 while the experimental set-up and the dimensions are shown in Figure 8. An average wind speed of $4.5 \mathrm{~m} / \mathrm{s} \pm 0.2 \mathrm{~m} / \mathrm{s}$ was used for the experiments. The wind speed was measured using a Vane-type anemometer. The measurements of the wind speed were taken downstream of Industrial fans which were arranged in array to covers a cross-section of $1.0 \mathrm{~m}$ by $1.0 \mathrm{~m}$ downstream of the fan as shown in the experimental set up in Figure 8. To conform to spatial uniformity, the blower was directed orthogonal to the test section area. The rotational speed was measured continuously in seconds interval until the stabilized rotational speed of the rotor is achieved. The rotational speed, current and voltage of the hybrid VAWT were measured using a multimeter and a hand held tachometer while the coefficient of power, and torque, and tip speed ratio were calculated using the equation 1,2 and 3 .

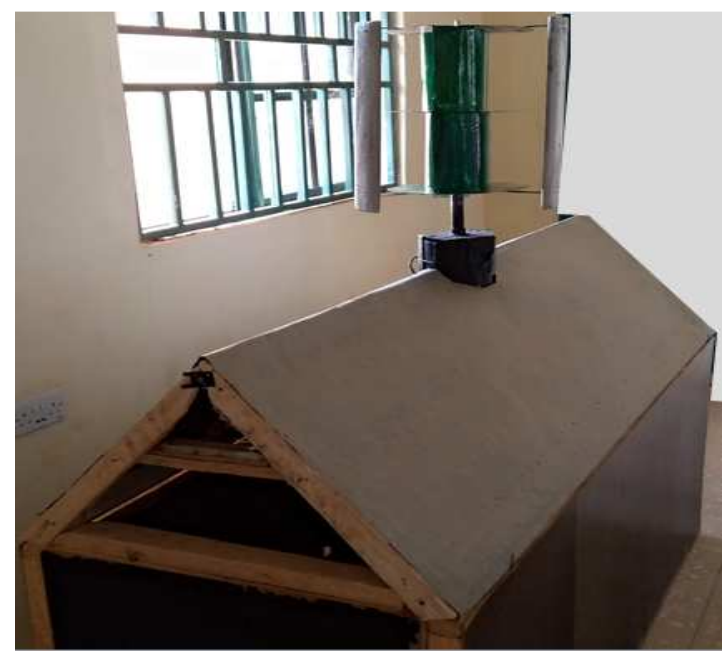

Figure 7. Buildng model integrated with hybrid VAWT.

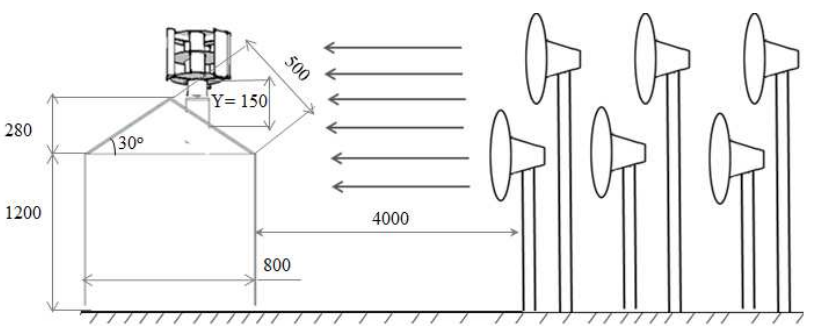

Figure 8. Dimensions of a building model integrated with a hybrid VAWT and dimension of the Industrial fans (all dimensions in $\mathrm{mm}$ ).

\section{Results and Discussion}

For this work, a hybrid VAWT turbine integrated on a building rooftop was designed and tested in an experiment in order to investigate its performance on a building rooftop. The hybrid VAWT was mounted at a height of $Y=150 \mathrm{~mm}$ above the rooftop, and on this position, experiments were conducted in two configurations; the first configuration investigates the performance of the bare-hybrid VAWT (without the building), while the second configuration investigates the performance of the hybrid VAWT integrated onto a building with a vaulted rooftop. The results obtained from these studies are presented as follows;

Figure 9 presents the rotational speed of the bare-hybrid VAWT and the building integrated hybrid VAWT against the time. As depicted in the figure, the trends of the rotational speed (RPM) continue to increase with time, and stabilized after reaching a steady state. The result further shows the contribution of the hybrid VAWTs both as bare-VAWTs and as building integrated hybrid VAWT. Firstly, the hybrid VAWT was tested without integrating on the building (barehybrid VAWT). The results obtained showed that the barehybrid VAWT can attain a maximum RPM of $335 \mathrm{rpm}$ at 222 seconds. However, when the hybrid VAWT was integrated onto the building rooftop under similar experimental conditions, the results shows that maximum RPM of $444 \mathrm{rpm}$ was obtained at 69 seconds. The results indicate that integrating the hybrid VAWT on a building rooftop increases the rpm by $33 \%$ compared to the bare-hybrid VAWT. 


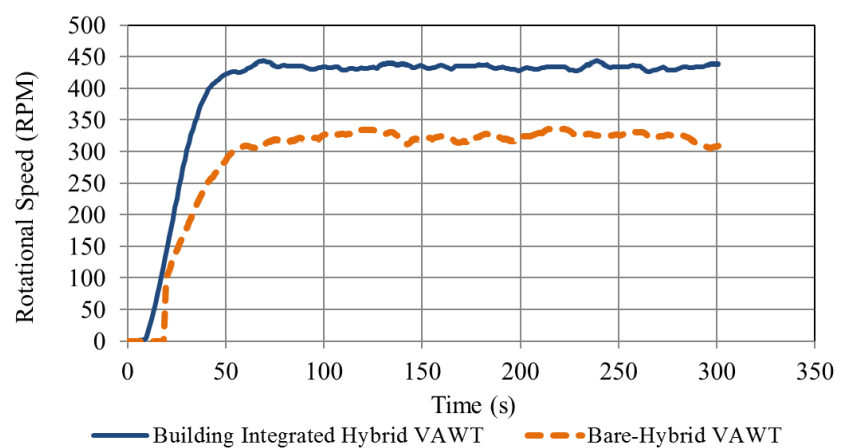

Figure 9. Rotational speed against time for building integrated hybrid VAWT and Bare-hybrid VAWT.

Figure 10 presents the coefficient of power, $C_{p}$ values against the tip speed ratio, TSR $(\lambda)$ for both the bare VAWThybrid, and the building integrated hybrid VAWT. From the figures, it can be seen that the $C_{p}$ values increases with TSR, and attain peak value at a certain TSR before decreasing with increase in TSR. It can be observed from the figure that the bare-hybrid VAWT attain a maximum $\mathrm{C}_{\mathrm{p}}$ value of 0.112 at TSR $(\lambda)$ of 1.15. However, under similar experimental condition the hybrid VAWT was integrated on the building rooftop and tested, the results showed that the building integrated hybrid VAWT attain a maximum $\mathrm{C}_{\mathrm{p}}$ of 0.182 at TSR, $(\lambda)$ of 1.32 , indicating an increment of $63 \%$ in $C_{p}$ value compared to the bare-hybrid VAWT.

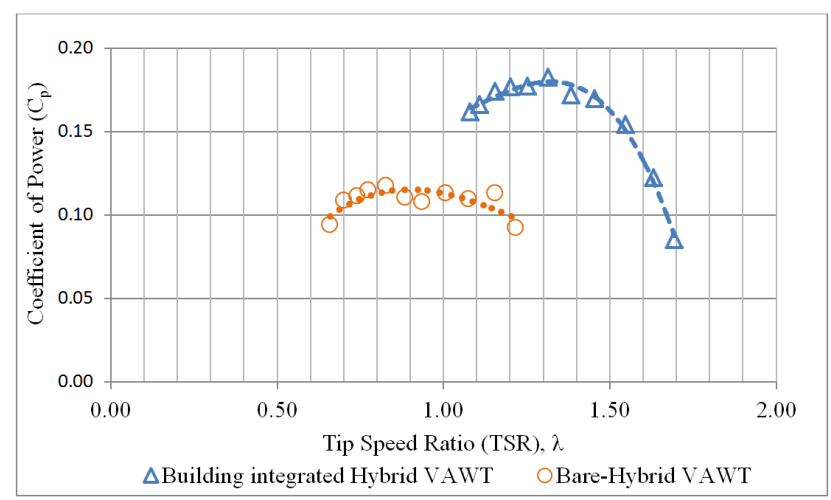

Figure 10. Coefficient of power against tip speed ration for building integrated hybrid VAWT and Bare- hybrid VAWT.

The increment in the $C_{p}$ and rpm values by the building integrated hybrid VAWT is due to the increase in wind speed experience by the hybrid VAWT on the building rooftop since the energy yields by wind turbine is directly proportional to the cube of the wind speed, this implies that any slight increment in the wind speed can lead to substantial increment in the power output hence the reason why the hybrid VAWT mounted on the rooftop of the building performs better than the bare-hybrid VAWT. Therefore mounting hybrid VAWT on the building yield $63 \%$ more power compared to bare-hybrid VAWT (without the building). This result is in agreement with Abohela et al. [50]. Similar studies by Puspitasari et al. [51] shows that they were able to achieved a $C_{p}$ value of 0.20 which indicates $48 \%$ increase in the power coefficient. The power coefficient is slightly higher because the operating condition is not the same and the wind speed is $10 \mathrm{~m} / \mathrm{s}$ as regard to the $4.5 \mathrm{~m} / \mathrm{s}$ used in this study. Furthermore, Hosseini and Goudarzi [38] achieved 40\% increment in the power coefficient of the hybrid VAWT although the operating conditions are not the same.

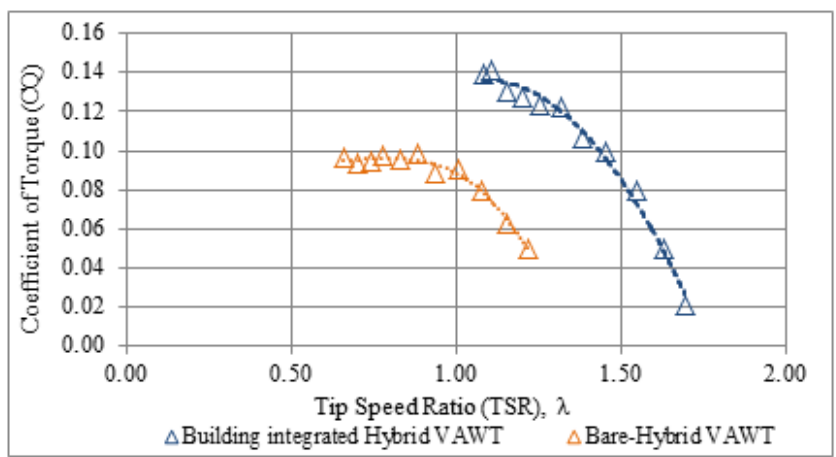

Figure 11. Coefficient of Torque verses tip speed ratio for building integrated hybrid VAWT and bare-hybrid VAWT.

Figure 11 presents the $\mathrm{C}_{\mathrm{Q}}-\lambda$ curves for the building integrated hybrid VAWT and the bare-hybrid VAWT. The figures indicates that the $C_{Q}$ values for both configurations decreases gradually with increase in the tip spee ratio $(\lambda)$. For the bare- hybrid VAWT, a maximun $\mathrm{C}_{\mathrm{Q}}$ value of 0.098 was obtained at $\lambda$ of 0.88 , however when the hybrid VAWT was integrated onto the building rooftop, th $\mathrm{C}_{\mathrm{Q}}$ values increases from a value of 0.098 to 0.141 at $\lambda$ of 1.11 . that the $C_{Q}$ values of the building integrated hybrid VAWTs increases by $44 \%$ which indicate that the building integrated hybrid VAWT has greater torque coefficient compared to the bare-hybrid VAWT. However, similar studies by Puspitasari et al. [51] showed that they are able to achieve a $C_{Q}$ value of 0.129 which indicates $29 \%$ increase in the power coefficient.

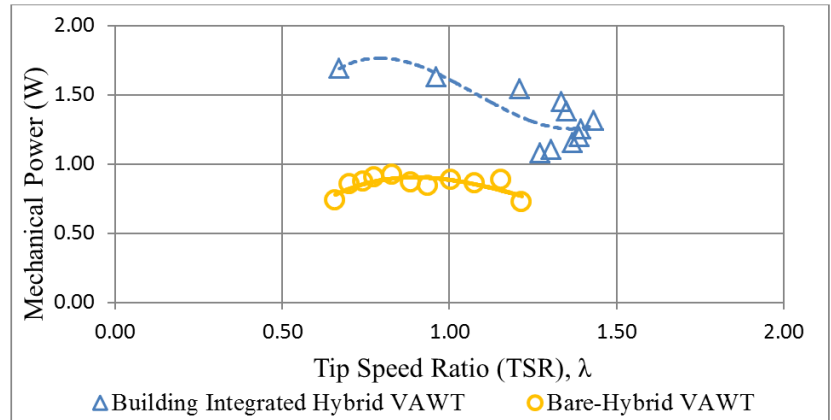

Figure 12. Power against Tip speed ratio (TSR) for Building integrated Hybrid VAWT and bare-hybrid VAWT.

In addition, Figure 12 presents the power generated by the building integrated hybrid VAWT and the bare-hybrid VAWT. The mechanical power extracted was plotted against the tip speed ratio (TSR), $\lambda$. It can be seen from the figure that the maximum power produce by the bare-hybrid VAWT is 0.922 $\mathrm{W}$ at TSR of 0.78 , however, when the hybrid VAWT was integrated on the building rooftop, the maximum power produced by the hybrid VAWTs increases from $0.922 \mathrm{~W}$ to $1.431 \mathrm{~W}$ under similar experimental conditions. The Figure 
indicates that mounting the hybrid VAWT on building rooftop produces higher power compared to the bare-hybrid VAWT. The maximum power produced by the building integrated hybrid VAWT increases by $55 \%$ compared to the bare-VAWT. The results are summarized in Table 2.

Table 2. Summary of experimental result.

\begin{tabular}{llll}
\hline Parameter & $\begin{array}{l}\text { Building integrated } \\
\text { hybrid VAWT }\end{array}$ & $\begin{array}{l}\text { Bare-hybrid } \\
\text { VAWT }\end{array}$ & $\begin{array}{l}\text { Increment } \\
(\%)\end{array}$ \\
\hline RPM & 444 & 335 & 33 \\
$\mathrm{C}_{\mathrm{p}, \max }$ & 0.182 & 0.0112 & 63 \\
TSR $(\lambda)$ & 1.32 & 1.15 & - \\
$\mathrm{C}_{\mathrm{Q} \max }$ & 0.141 & 0.098 & 44 \\
TSR $(\lambda)$ & 1.11 & 0.88 & - \\
$\mathrm{P}_{\text {mech, } \max }$ & 1.431 & 0.922 & 55 \\
TSR $(\lambda)$ & 1.32 & 0.78 & - \\
\hline
\end{tabular}

The improved performance of hybrid VAWT on the rooftop is attributed to the increased wind speed at the rooftop which translate into more power compared to the bare-hybrid VAWT. Furthermore, Abohela et al. [50] asserted that installation of wind turbine on the buildings allows the turbine to take advantage of the local increment of the unperturbed wind speed due to the well- known "hill effect" which states that up to $20 \%$ of the unperturbed wind sped (depending on both the incoming wind direction and the orientation of the building) can be utilized by the wind turbine. The building rooftop serves as an augmentation device that further increases the wind speed due to the speed up effect at the rooftop. Moreover, the rooftop deflect and direct the deflected airflow to a certain angle known as the skewed angle. Better performance is expected to be achieved at high skewed angle. According to Chong et al. [1] and Degrassi, et al. [52], when the skewed angle is high, the swept area of the turbine is increased due to the contribution of the downwind zone which counterparts the decrease of the projected frontal area with an overall increase of the available surface area to intercept the wind. The region of interaction of the downwind blade passage with the upwind generated wake is modified by the skewed flow; this has helped to increase therefore increasing the performance of hybrid VAWT on the rooftop compared to the bare-hybrid VAWT. When the skewed angle is increased, the area of the downwind blade passage which is operating outside the upwind generated wake will also increase thus experiencing an incoming flow with larger energy content [53].

The rooftop takes the advantage of the "roof effect" whereby the wind impacts the surface of the sloped face of the roof and deflects the airflow upwards towards the ridge, thus directing the wind stream at a better angle of attack of the vertical wind. Furthermore, the rooftop wind turbine experience more turbulence compared to the free standing wind turbine (without roof). Based on previous researches, turbulence intensity actually improves the performance of wind turbines [54-56], also Lubitz. [57] Asserted that the power extraction is proportional to the square of the relative velocity at the blade which increases with increase in turbulence.

\section{Conclusion}

Wind turbines in the built environment have the potential to provide an on-site energy generation for buildings, which will minimize both cost and loss of energy due to transmission when it is mounted outside the built environment. In this work, a hybrid vertical axis wind turbine was designed and tested in an experiment, the performance of the building integrated hybrid VAWT was investigated and compared to the bare-hybrid VAWT (without the building). The results obtained from the study indicate that the hybrid VAWT mounted on the building can potentially displace a stand-alone (bare-hybrid) VAWT and provide on-site energy generation for the building. Results from the study show that hybrid VAWTs integrated on a building with gable rooftop would yield up to $63 \%$ more energy compared to the bare-hybrid VAWT under similar experimental conditions. This shows that that the building rooftop can significantly increase the performance of wind turbines when integrated on top of the building and thus has positive effects on the performance of the hybrid VAWT. Future work will include testing the hybrid VAWT using different wind speed, wind direction, and simulation of the airflow and turbulence intensity using computational fluid dynamics.

\section{Acknowledgements}

The authors would like to thank the Tertiary Education Trust Fund (TETFUND) for the Research Grant allocated (institutional based grant, IBR 2019) through the Kebbi State University of Science and Technology, Aliero.

\section{References}

[1] Chong, W. T., Gwani, M., Tan, C. J., Muzammil, W. K., Poh, S. C., and Wong, K. H., (2017) "Design and Testing of a Novel Buidiing Integrated Cross Axis Wind Turbine," Applied Sciences, vol. 7, pp. 1-21

[2] Bahaj, A. S., Myers, L., and James, P. A. B., (2007) "Urban energy generation: Influence of micro-wind turbine output on electricity consumption in buildings," Energy and Buildings, vol. 39, pp. 154-165.

[3] Raymond, E. P. and Winchester, V., "Roof Ridge wind turbine" US Patent US 2010/0126086 A1, 2010.

[4] Peacock, A. D., Jenkins, D., Ahadzi, M., Berry, A., and Turan, S., (2008) "Micro wind turbines in the UK domestic sector," Energy and Buildings, vol. 40, pp. 1324-1333.

[5] Drew, D., Barlow, J., and Cockerill, T., (2013) "Estimating the potential yield of small wind turbines in urban areas; A case study of Greater London UK," Journal of Wind Energy and Industrial Aerodynamic, vol. 115, pp. 104-111.

[6] Muller, G., Jentsch, M., and Stoddart, E., (2009) "Vertical axis resistance type wind turbines for use in buildings," Renewable Energy, vol. 34, pp. 1407-1412.

[7] Booker, J., Mellor, P., Wrobel, R., and Drury, D., (2010) "A compact, high efficiency contra-rotating generator suitable for wind turbines in the urban environment.," Renewable Energy, vol. 35, pp. 2027-2033. 
[8] Henriques, J., Marques da Silva, F., Estanqueiro, A., and Gato, L., (2009) "Design of a new urban wind turbine airfoil using a pressure-load inverse method.," Renewable Energy, vol. 34, pp. 2728-2734.

[9] Abohela, I., N. Hamza, and Dudek, S., "Urban Wind Turbines Integration in the Built Form and Environment," Newcastle University 2011.

[10] Beller, C., "Energy Output Estimation for a Small Wind Turbine Positioned on a Rooftop in the Urban Environment with and without a Duct," National Laborator for Sustainable Energy 0106-2840 ISSN 978-87-550-3721-2, 2011.

[11] Perwita Sari, D., "Measurement of the Influence of Roof Pitch to Increasing Wind Power Density," in Conference and Exhibition Indonesia - New, Renewable Energy and Energy Concervation, [The $3 \mathrm{rd}$ Indo EBTKE ConEx 2014], Indonesia, 2015 pp. $42-47$.

[12] Dutton, A. G., Halliday, J. A., and Halliday, M. J., (2005) "The Feasibility of Building Mounted/Integrated Wind Turbines (BUWTs): Achieving their Potential for Carbon Emission Reductions," pp. 1-109.

[13] Miles, C. (2006). Survey of Urban Wind Energy Technology for Sustainability and the Built Environment. Available: https://extension.ucdavis.edu

[14] Mertens, S., Kuik, G. V., and van Bussel, G., (2003) "Performance of an H-Darrieus in the skewed flow on a roof $^{1}, "$ Journal of Solar Energy Engineering, vol. 125, pp. 433-440.

[15] Chong, W. T., Wan Khairul M., Kok-Hoe W., Wang, C. T., Gwani, M., Chu, Y. J., et al., (2017) "Cross axis wind turbine: Pushing the limit of wind turbine technology with complementary design," Applied Energy, vol. 207, pp. 98-95.

[16] Ricci, R., Romagnoli, R., Montelpare, S., and Vitali, D., (2016) "Experimental study on a Savonius wind rotor for street lighting systems," Applied Energy, vol. 161, pp. 143-52.

[17] Hau, E., ("Wind turbines: fundamentals, technologies, application, economics.," 2nd ed. New York: Springer; 2006.

[18] Brulle, R., (1977) "Feasibility investigation of the giromill for generation of electrical power.," Energy Research and Development Administration.

[19] Alam, J. M. and Iqbal, M. T., (2009) "Design and development of hybrid vertical axis turbine" IEEE, pp. 1178-1183.

[20] Dominy, R., Lunt, P., Bickerdyke, A., and Dominy, J., (2007) "Self-starting capability of a Darrieus turbine," Journal of Power and Energy, vol. Proc. IMechE 221 Part A.

[21] Hill, N., Dominy, R., Ingram, G., and Dominy, J., (2009) "Darrieus turbines: the physics of self-starting," Journal of Power and Energy, vol. ImechE 223 Part A, pp. 21-29.

[22] Kirke, B. K., "Evaluation of Self-Starting Vertical axis Wind Turbines For Stand-alone Applications," Ph.D, School of Engineering Griffith University Gold Coast Campus, 1998.

[23] Takao, M., Kuma, H., Maeda, T., Kamada, Y., Oki, M., and Minoda, A., (2009) "A straight-bladed vertical axis wind turbine with a directed guide vane row; Effect of guide vane geometry on the performance" Journal of Thermal Science, vol. 18 , pp. 54-57.

[24] Kim, D. and Gharib, M., (2013) "Efficiency improvement of straight-bladed vertical-axis wind turbines with an upstream deflector.," Journal of Wind Engineering and Industrial Aerodynamics, vol. 115, pp. 48-52.

[25] Stout, C., Arnott, S., and Islam, S., (2017) "Efficiency improvement of vertical axis wind turbines with an upstreamdeflector efficiency improvement of vertical axis wind turbines with an upstream deflector," Energy Procedia, vol. 118, p. 9 .

[26] Menet, J.-L., (2004) "Adouble-step Savonius rotor for local production of electricity: a design study," Renewable Energy, vol. 29 , pp. $1843-1862$.

[27] Sanusi, A., Soeparman, S., Wahyudi, S., and Yuliati, L., (2016) "Experimental study of combined blade savonius wind turbine," International Journal of Renewable Energy Research, vol. 6, pp. 615-619.

[28] Thiyagaraj, J., Rahamathullah, I., Prabu, P. S., and 2016., (2016) "Experimental investigations on the performance characteristics of a modified four bladed Savonius hydrokinetic turbine " International Journal of Renewable Energy Research, vol. 5, pp. 1530-1536.

[29] Sharma, S., Sharma, R. K., and 2016., (2016) "Performance improvement of Savonius rotor using multiple quarter blades - A CFD investigation," Energy Conversion andManagement, vol. 127.

[30] Kailash, G., Eldho, T. I., and Prabhu, S. V., (2012) "Performance study of modified savonius water turbine with two deflector plates," International Journal of Rotating Machinery, vol. Article ID 679247, p. 12

[31] Darhmaoui, H. and Sheikh, N., (2017) "Savonius Vertical Wind Turbine: Design, and Simulation " Thesis Al Akhawayn University.

[32] Lane, J., Lynn, T., Rafieck, S., and Rossen, M. T., (2018) "Vertical axis wind turbine for remote power generation, (unpublished ) Ph.D thesis, Worcester Polytechnic Institute, 77-80".

[33] Letcher, T., "Title," unpublished|.

[34] Sahim, K., Santoso, D., and Puspitasari, D., (2018) "Investigations on the Effect of Radius Rotor in Combined Darrieus-Savonius Wind Turbine," Hindawi International Journal of Rotating Machinery, p. 7 pages.

[35] Siddiqui, M. S., Durrani, N., and Akhtar, I., (2015) "Quantitification of the effects of geometric approximation on the performance of a vertical axis wind turbine," Renew Energy, vol. 74, pp. 661-670

[36] Gwani, M., Mamuda, B., Umar, M. K., and John, D., (2020) "Design, Fabrication and Performance Evaluation of Hybrid Vertical Axis Wind Turbine," International Journal for Modern Trends in Science and Technology, vol. 6, pp. 80-86.

[37] Wekesa, D. W., Saoke, C. O., and Kamau, J., (2020) "An experimental investigation into performance characteristics of H-shaped and Savonius-type VAWT rotors," Scientific Africa, vol. 10, pp. 1-11.

[38] Hosseini, A. and Goudarzi, N., (2019) "Design and CFD study of a hybrid vertical-axis wind turbine by employing a combined Bach-type and H-Darrieus rotor systems," Energy Conversion \& Management., vol. 189, pp. 49-59. 
[39] Walker, S. L., (2011) "Building mounted wind turbines and their suitability for the urban scale- a review of methods of estimating urban wind resource," Energy and Buildings, vol. 43, pp. 1852-1862.

[40] Lu, L. and Sun, K., (2014) "Wind power evaluation and utilization over a reference high-risebuilding in urban area," Energy and Buildings, vol. 68, pp. 339-350.

[41] Ledo, L., Koshasih, P. B., and Cooper, P., (2011) "Roof mounting site analsysis for micro-wind turbines," Renewable Energy, vol. 36, pp. 1379-1391.

[42] Blackmore, P., Siting micro-wind turbines on house roofs. Watford: BRE., 2008.

[43] WINEUR, "Wind Energy Integration in the Urban Environment," European Commission2007.

[44] Wang, B., Cotb, L. D., Adolphec, L., Geoffroya, S., and Morchaind, J., (2015) "Estimation of wind energy over roof of two perpendicular buildings," Energy and Buildings, vol. 88, pp. 57-67.

[45] Padmanabhan, K. K., (2013) "Study on increasing wind power in buildings using TRIZ Tool in urban areas," Energy and Buildings, vol. 61, pp. 344-348.

[46] Mertens, S., Delft, T., and Holland, (2002) "Wind energy in urban areas: Concentration effects for wind turbine close to buildings," Refocus, pp. pp. 22-24.

[47] Mithraratne, N., (2009) "Roof-top wind turbines for microgeneration in urban houses in New Zealand," Energy and Buildings, vol. 41, pp. 1013-1018.

[48] Abohela, I., Hamza, N., and Dudek, D., "Effect of Roof Shape on Energy Yield and Positioning of Roof Mounted Wind Turbines," presented at the 12th Conference of International Building Performance Simulation Association, Sydney, 2011.

[49] Loganathan, B., Chowdhury, H., Mustary, I., Rana, M. M., and Alam, F., (2019) "Design of a micro wind turbine and its economic feasibility study for residential power generation in built-up areas," 2nd International Conference on Energy and Power, ICEP2018, 13-15 December 2018, , vol. 160, pp. 812819.

[50] Abohela, I., Hamza, N., and Dudek, S., (2013) "Effect of roof shape, wind direction, building height and urban configuration on the energy yield and positioning of roof mounted wind turbines," Renewable Energy, vol. 50, pp. 1106-1118.

[51] Puspitasari, D. and Sahim, K., (2019) "Effect of Savonius blade height on the performance of a hybrid DarrieusSavonius wind turbine," Journal of Mechanical Engineering and Sciences, vol. 13, pp. 2289-4659; e-ISSN: 2231-8380.

[52] Degrassi, S., Castelli, M. R., and Benini, E., (2013) "A Retrospective of Wind Turbine Architectural Integration in the Built Environment," World Academy of Science, Engineering and Technology vol. 78, p. 379.

[53] Bianchini, A., Ferrara, G., Ferrari, L., and Magnani, S., (2012) "An Improved Model for the Performance Estimation of an HDarrieus Wind Turbine in Skewed Flow," Wind Engineering, vol. 36, pp. 667-686.

[54] Ferreira, C., "Wind tunnel hotwire measurements, flow visualization and thrust measurement of a VAWT in skew," in 44th AIAA Aerospace Sciences Meeting and Exhibit, Reno, Nevada, 2006, p. AIAA 1368.

[55] Kurt S. Hansen, Rebecca J. Barthelmie, Leo E. Jensen, and Sommer, A., (2012) "The impact of turbulence intensity and atmospheric stability on power deficits due to wind turbine wakes at Horns Rev. wind farm," Wind Energy vol. 15, pp. 183-196.

[56] Sanderse, B., "Aerodynamics of wind turbine wakes: Literature review," Energy research center of Netherland (ECN), Netherland, ECN-e--09-016. 2009.

[57] Lubitz, W. D., (2014) "Impact of ambient turbulence on performance of a small wind turbine," Renewable Energy, vol. 61, pp. 69-73. 